\title{
Chylothorax Associated with Chronic Lymphocytic Leukemia
}

\author{
Osamu Kohmoto ${ }^{1}$, Kazumi Kawabe ${ }^{1}$, Hideya Ono ${ }^{1}$, Ryuta Yanagimoto ${ }^{1}$, Junji Arimoto ${ }^{2}$, \\ Atsutoshi Hatada ${ }^{3}$, Tadatoshi Suruda ${ }^{1}$ and Yoshiaki Minakata ${ }^{1}$
}

\begin{abstract}
An 80-year-old man who had suffered from chronic lymphocytic leukemia (CLL) and achieved complete remission was admitted to our hospital due to right pleural effusion. Thoracentesis revealed that the effusion was chyle. Lymphoscintigraphy showed an obstruction of the thoracic duct below the sternum. CD45-gated flow cytometry of the pleural effusion showed elevated numbers of CD5- and CD23-positive lymphocytes and a high serum level of soluble interleukin-2 receptor. These results suggested that the chylothorax was caused by the obstruction of the thoracic duct by the sludging of either abnormal lymphocytes of CLL or transformed malignant lymphoma cells.
\end{abstract}

Key words: CLL, malignant lymphoma, Richter syndrome, lymphoscintigraphy

(Intern Med 55: 3641-3644, 2016)

(DOI: 10.2169/internalmedicine.55.7250)

\section{Introduction}

Chylothorax is mainly caused by either a malignant tumor or traumatic injury. Among malignant tumors, malignant lymphoma is the most frequent cause of chylothorax. The mechanism of chylothorax formation in malignant lymphoma is mainly the obstruction and rupture of the thoracic duct by enlarged lymph nodes. A few reports have described chronic lymphocytic leukemia (CLL) as a cause of chylothorax, and CLL is known to be capable of transforming into malignant lymphoma. We employed lymphoscintigraphy and CD45-gated flow cytometry of the pleural effusion to diagnose the cause of the chylothorax and considered its mechanisms.

\section{Case Report}

An 80-year-old man visited our hospital due to right pleural effusion in August 2014. He had a history of diabetes mellitus (DM), bladder cancer, chronic obstructive pulmonary disease (COPD), CLL which was in complete remission since 1990, and a right rib fracture in December 2013.
He was an ex-smoker (45 pack-years) and quit smoking when he was 50 years old.

A physical examination showed that his percutaneous oxygen saturation was $98 \%$, blood pressure $122 / 80 \mathrm{mmHg}$, heart rate $80 / \mathrm{min}$, respiratory rate $25 / \mathrm{min}$, and body temperature $36.9^{\circ} \mathrm{C}$. The heart sounds were pure, the rhythm was regular, and the breath sounds were clear in both lung fields. The abdomen was flat and soft without tenderness. No lymphadenopathy or edema in the extremities was noted.

A chest radiograph revealed a scar from a right rib fracture and a moderate amount of pleural effusion. A CT scan showed right pleural effusion and a right renal cyst without any lymphadenopathy (Fig. 1). The values obtained on an electrocardiogram were within the normal limits.

The laboratory data showed elevations in the white blood cell count $(24,800 / \mu \mathrm{L})$, ratio of lymphocytes $(91.7 \%)$, glycosylated hemoglobin A1c level (7.3\%), and brain natriuretic peptide level $(28.2 \mathrm{pg} / \mathrm{mL})$. In addition, the level of soluble interleukin-2 receptor (sIL-2R) was highly elevated $(2,289$ $\mathrm{U} / \mathrm{mL}$ ). Only slight anemia and renal dysfunction were found, neither of which was clinically important. The findings from other biochemical and immunological examinations were near normal values.

${ }^{1}$ Department of Respiratory Medicine, National Hospital Organization Wakayama Hospital, Japan, ${ }^{2}$ Department of Surgery, National Hospital Organization Wakayama Hospital, Japan and ${ }^{3}$ Department of Surgery, Saiseikai Wakayama Hospital, Japan

Received for publication February 8, 2016; Accepted for publication April 18, 2016

Correspondence to Dr. Yoshiaki Minakata, minakaty@wakayama2.hosp.go.jp 

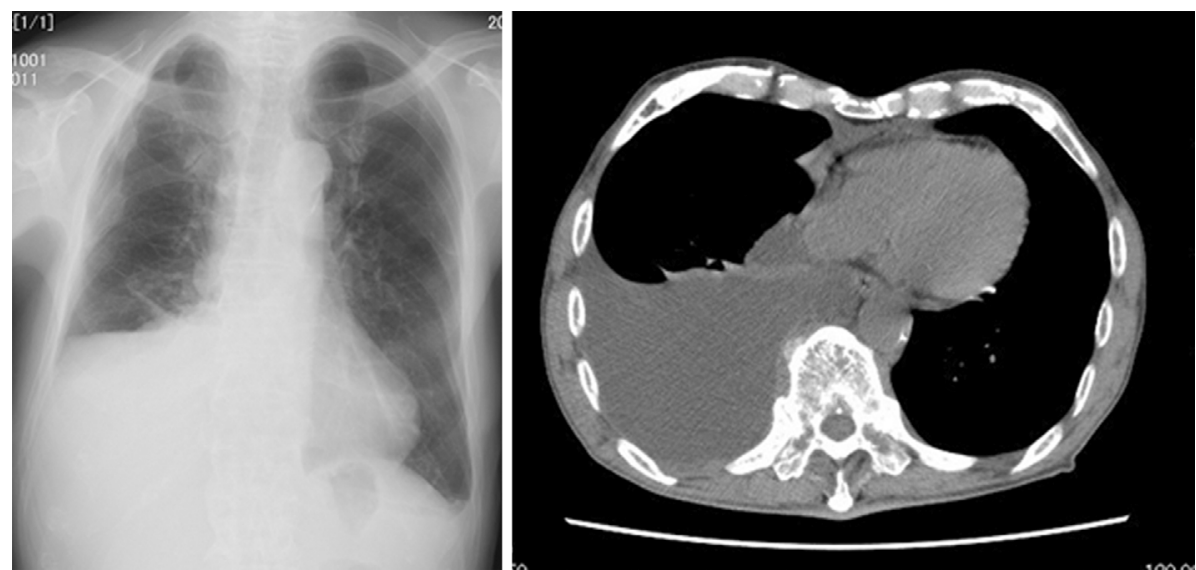

Figure 1. Chest X-ray and CT images on admission.

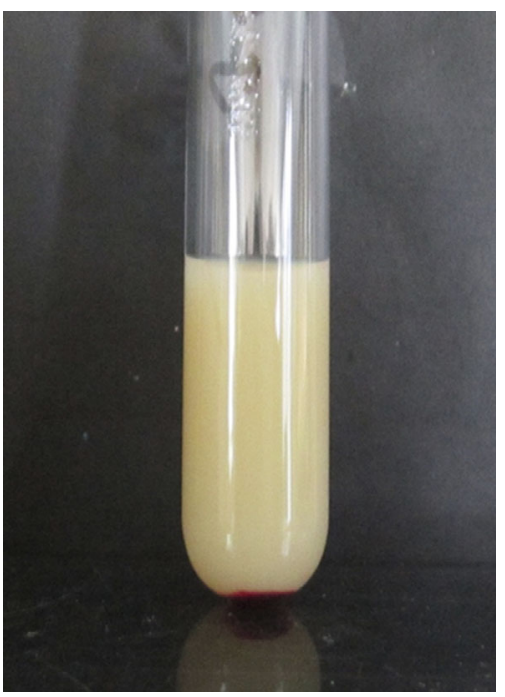

Figure 2. Appearance of pleural effusion.

The pleural fluid was yellow and cloudy with a high concentration of triglycerides $(576 \mathrm{mg} / \mathrm{dL})$, especially chylomicron (28\%) (Fig. 2). The cytology of the pleural effusion was class II with lymphocyte predominance. Neither bacteria nor mycobacteria were detected.

Lymphoscintigraphy showed an obstruction of the thoracic duct below the sternum (Fig. 3). Given that the most frequent cause of chylothorax is malignant lymphoma, we performed CD45-gated flow cytometry of the pleural effusion and found increased numbers of CD5-positive (99.5\%), CD23-positive (70.0\%), CD20-positive (45.3\%), and CD10negative $(0.5 \%)$ lymphocytes (Fig. 4). This surface antigen pattern implied that the cells in the pleural effusion were CLL or small lymphocytic lymphoma. In addition, given the elevated values of sIL-2R, our diagnosis was that a relapse of CLL or transformation of CLL to malignant lymphoma had occurred. We then reintroduced the patient to the Department of Hematology at the university hospital and started him on chemotherapy with 4 courses of fludarabine $40 \mathrm{mg}$ for 3 days.

\section{Discussion}

We experienced a case of chylothorax with a history of CLL that was in complete remission. Lymphoscintigraphy revealed an obstruction of the thoracic duct without compression by the lymph nodes or rupture and detected CD5and CD23-positive lymphocytes in the chyle, which suggested that the chylothorax was associated with CLL.

Generally, chylothorax is mainly caused by a malignant tumor or traumatic injury (1-5). Valentine et al. reported that $46 \%$ of chylothorax cases were caused by malignant tumors, $28 \%$ by a traumatic injury, and $14 \%$ were idiopathic. Furthermore, malignant lymphoma comprises $70 \%$ of the malignant tumors (1). In the present case, given that the patient had a recent history of right rib fracture and complete remission of CLL, we initially considered both a traumatic injury and a malignant tumor as potential causes of the chylothorax.

Chylothorax caused by a traumatic injury of the thoracic duct usually recovers quickly and disappears in two or three months (6) and rarely lasts for eight months. In cases of severe traumatic injury, large amounts of pleural fluid and some respiratory symptoms may be observed. In the present case, however, the chylothorax continued for eight months after the rib fracture, and neither respiratory symptoms nor findings of thoracic duct injury were observed. Therefore, the traumatic injury did not seem to be the reason for the chylothorax in the present case.

We performed CD45-gated flow cytometry of the pleural effusion, because most reported cases of chylothorax are caused by malignant lymphoma. The flow cytometry findings revealed increased numbers of CD5-positive, CD20positive, CD23-positive, and CD10-negative lymphocytes, along with an elevated IL-2R level, suggesting that the cells were from CLL or small lymphocytic lymphoma $(7,8)$.

Cases in which CLL caused chylothorax have been sporadically reported, but the mechanism remains unclear. Rice et al. suggested three possible mechanisms by which CLL might cause chylohorax (9). The most common mechanism 


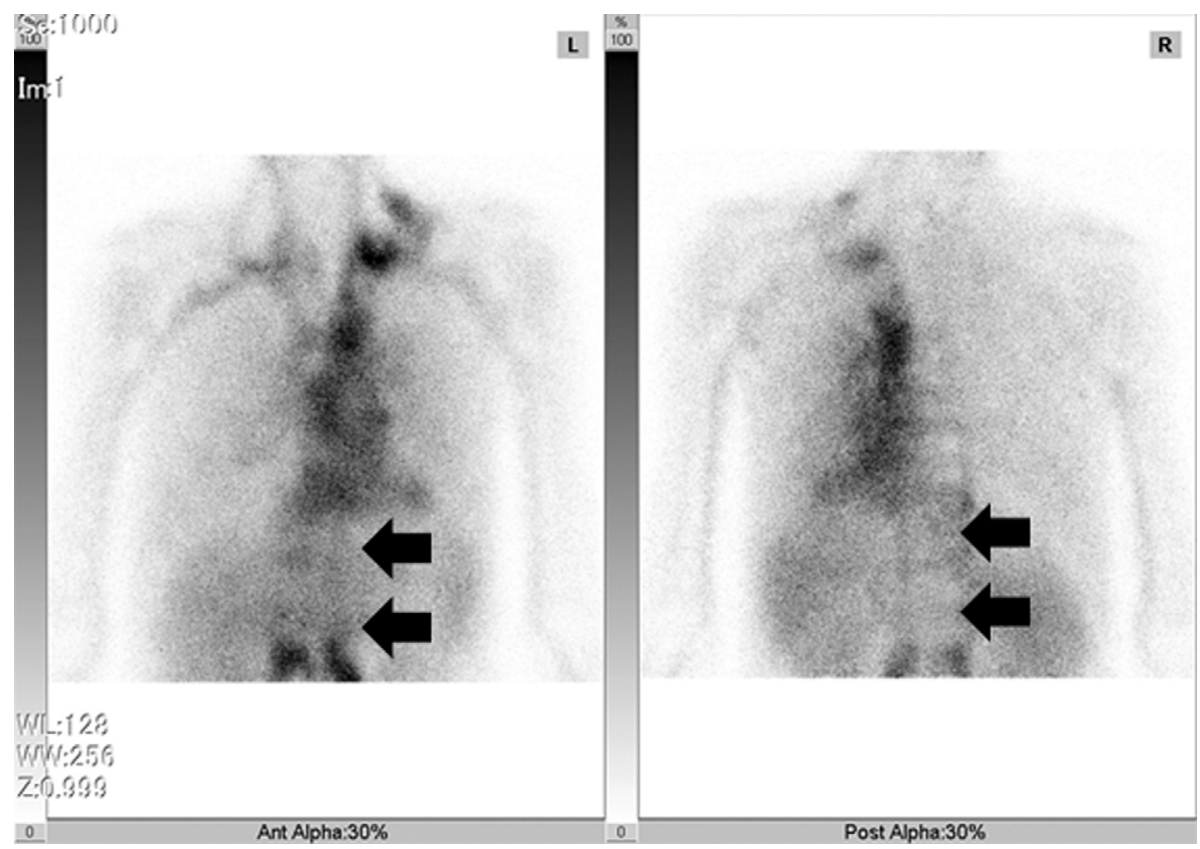

Figure 3. Lymphoscintigraphy of the patient, left: anterior image; right: posterior image. Arrows indicate part of the obstruction.

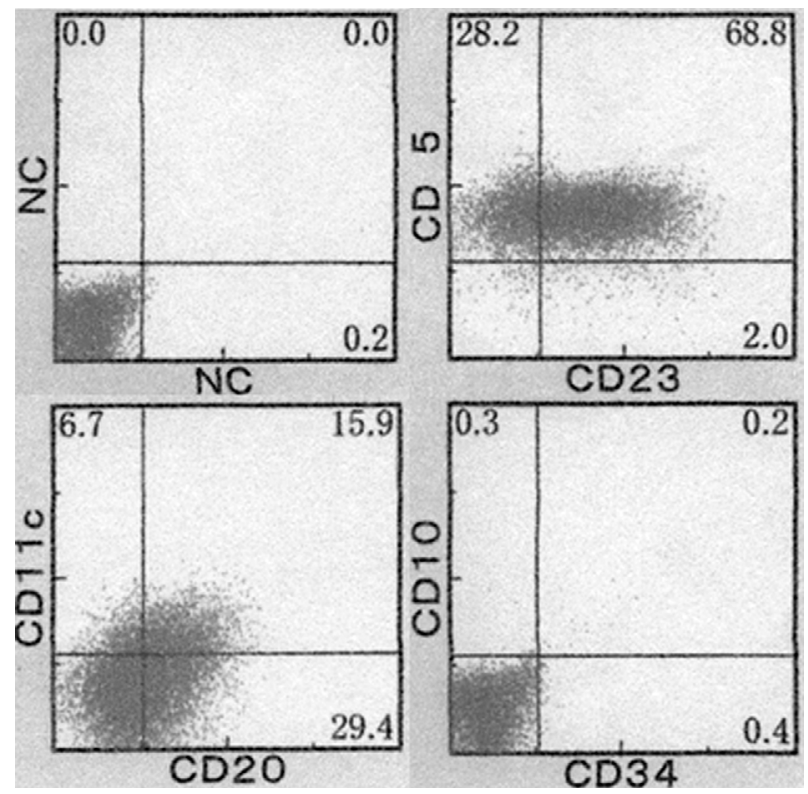

Figure 4. CD45-gated flow cytometry of pleural effusion. CD5: 99.5\%, CD23: 70.0\%, CD20: $45.3 \%$, CD10: $0.5 \%$.

is mediastinal lymphadenopathy (2). Although CLL rarely causes significant mediastinal lymphadenopathy, such cases may be at risk for developing chylothorax. The second possible mechanism involves the flow of leukemic lymphocytes through the lymphatic system. The presence of an extremely large number of abnormal lymphocytes in CLL may cause sludging in the lymphatic system, which may result in either a pseudo-obstruction of the thoracic duct or lymphatic drainage into the pleura, resulting in chylothorax. The third possible mechanism involves the traumatic disruption of the thoracic duct. Much like in patients who have just finished a high-fat meal, the large number of lymphocytes and sludging in CLL patients may distend the thoracic duct, making it more susceptible to rupture. Then, minor trauma, such as from a deep cough or violent sneeze, could result in microdisruptions of the thoracic duct and allow chyle to leak into the pleural space. In the present case, although neither mediastinal lymphadenopathy nor minor trauma were observed, the chylothorax may have been caused by a pseudoobstruction of the thoracic duct.

CLL sometimes transforms into malignant lymphoma, which is called "Richter syndrome", although the frequency of such a transformation is low (10-15). Rossi et al. reported that such transformations only occur in $2-7 \%$ of cases (11), while Yamasaki et al. reported that it occurred in 3$10 \%$ (12). Given the highly elevated sIL-2R value and the fact that malignant lymphoma might more easily form a solid mass in the thoracic duct than CLL, the relapsed CLL may indeed have transformed into malignant lymphoma, forming an intra-ductal solid mass that obstructed the thoracic duct in the present case.

In summary, we experienced a case of chylothorax associated with chronic lymphocytic leukemia. The chylothorax may have been caused by the obstruction of the thoracic duct by the sludging of either abnormal lymphocytes of CLL or transformed malignant lymphoma.

The authors state that they have no Conflict of Interest (COI).

\section{Acknowledgement}

The authors thank Mr. Brent Bell for reading the manuscript.

\section{References}

1. Valentine VG, Raffin TA. The management of chylothorax. Chest 
102: 586-591, 1992.

2. Roy PH, Carr DH, Payne SW. The problem of chylothorax. Mayo Clin Proc 42: 457-467, 1967.

3. Agrawal V, Doelken P, Sahn S. Pleural fluid analysis in chylous pleural effusion. Chest 133: 1436-1441, 2008.

4. Talwar A, Lee HJ. A contemporary review of chylothorax. Indian J Chest Dis Allied Sci 50: 343-351, 2008.

5. Itoh Y, Honda Y, Teramoto S, Nakagawa A, Asakawa M, Kusajima K. A case of idiopathic chylothora. Nippon Kyobu Shikkan Gakkai Zasshi 31: 109-111, 1993 (in Japanese, Abstract in English).

6. McGrath EE, Blades Z, Anderson PB. Chylothorax: aetiology, diagnosis and therapeutic options. Respir Med 104: 1-8, 2010.

7. Green DJ, Pagel JM, Pantelias A, et al. Pretargeted radioimmunotherapy for B-cell lymphomas. Clin Cancer Res 13: 5598s-5603s, 2007.

8. Demurtas A, Accinelli G, Pacchioni D, et al. Utility of flow cytometry immunophenotyping in fine-needle aspirate cytologic diagnosis of non-Hodgkin lymphoma: A series of 252 cases and review of the literature. Appl Immunohistochem Mol Morphol 18 311-322, 2010

9. Rice TW, Milstone AP. Milstone. Chylothorax as a result of chronic lymphocytic leukemia: case report and review of the lit- erature. South Med J 97: 291-294, 2004.

10. Rossi D, Gaidano G. Richter syndrome: molecular insights and clinical perspectives. Hematol Oncol 27: 1-10, 2004.

11. Rossi D, Gaidano G. Richter syndrome. Adv Exp Med Biol 792: 173-191, 2013.

12. Yamazaki ML, Lum CA, Izumi AK. Primary cutaneous Richter syndrome: prognostic implications and review of the literature. $\mathrm{J}$ Am Acad Dermatol 60: 157-161, 2009.

13. Tsimberidou AM, Keating MJ. Richter syndrome. biology, inicidence, and therapeutic strategies. Cancer 103: 216-228, 2005.

14. Omoti CE, Omoti AE. Richter syndrome: a review of clinical, neurological and other manifestations. Br J Haematol 142: 709716, 2008.

15. Osmanov DSh, Kruglova GV, Probatova NA, et al. Richter's syndrome: analysis of literature data and original observations. Ter Arkh 71: 47-58, 1999.

The Internal Medicine is an Open Access article distributed under the Creative Commons Attribution-NonCommercial-NoDerivatives 4.0 International License. To view the details of this license, please visit (https://creativecommons.org/licenses/ by-nc-nd/4.0/).

(C) 2016 The Japanese Society of Internal Medicine http://www.naika.or.jp/imonline/index.html 